Research Paper

\title{
High Production of 2,3-butanediol by a Mutant Strain of the Newly Isolated Klebsiella pneumoniae SRP2 with Increased Tolerance Towards Glycerol
}

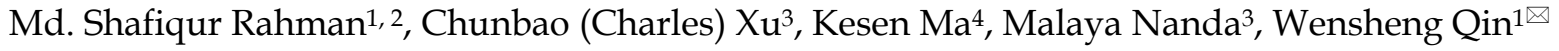 \\ 1. Department of Biology, Lakehead University, 955 Oliver Road, Thunder Bay, Ontario, P7B 5E1, Canada; \\ 2. Department of Microbiology, University of Chittagong, Bangladesh; \\ 3. Institute for Chemicals and Fuels from Alternative Resources (ICFAR), Western University, London, Ontario N6A 5B9, Canada; \\ 4. Department of Biology, University of Waterloo, 200 University Avenue West, Waterloo, Ontario, N2L 3G1, Canada. \\ $\square$ Corresponding author: Dr. Wensheng Qin, Department of Biology, Lakehead University, 955 Oliver Road, Thunder Bay, Ontario, P7B 5E1, Canada. Email:
} wqin@lakeheadu.ca; Phone: +1 807-343 8467; Fax: 807-346 7796.

(c) Ivyspring International Publisher. This is an open access article distributed under the terms of the Creative Commons Attribution (CC BY-NC) license (https://creativecommons.org/licenses/by-nc/4.0/). See http://ivyspring.com/terms for full terms and conditions.

Received: 2016.09.15; Accepted: 2016.09.30; Published: 2017.02.23

\begin{abstract}
Biodiesel, a renewable fuel produced by transesterification of animal fats and vegetable oils, generates about $10 \%(\mathrm{v} / \mathrm{v})$ of crude glycerol as a core byproduct. The high volume of this non bio-degradable glycerol is becoming of a great environmental and economical concern due to its worldwide ever-growing surplus. Herein we report a high production of 2,3-butanediol (2,3-BD) from pure and biodiesel derived crude glycerol using a mutant $K$. pneumoniae SRM2 obtained from a newly isolated strain Klebsiella pneumoniae SRP2. The mutant strain SRM2 with standing high glycerol concentration ( $220 \mathrm{~g} \mathrm{~L}^{-1}$ of medium) could rapidly convert glycerol aerobically to $2,3-\mathrm{BD}$, a versatile product extensively used in chemical, pharmaceutical and fuel industries Our study revealed that an increased GDH activity led to a substantially enhanced production of 2,3-BD. The mutant strain exhibited 1.3-fold higher activity of GDH than that of parent strain $(500.08$ vs. 638.6 $\mu \mathrm{mol} \mathrm{min}{ }^{-1} \mathrm{mg}^{-1}$ protein), yielding of $32.3 \mathrm{~g} \mathrm{~L}^{-1}$ and $77.5 \mathrm{~g} \mathrm{~L}^{-1} 2,3-\mathrm{BD}$ with glycerol in batch and fed-batch process respectively. However, in batch culture with crude glycerol, cell growth and glycerol consumption were expressively boosted, and 2,3-BD production was $27.7 \mathrm{~g} \mathrm{~L}^{-1}$ from 75.0 $\mathrm{g} / \mathrm{L}$ crude glycerol. In this report, the optimal conditions for high production of 2,3-BD were defined in a completely aerobic process, and $0.59 \mathrm{~g} \mathrm{~g}^{-1}$ product yield of 2,3-BD was attained by the mutated strain $K$. pneumoniae SRM2, which is the highest amount obtained from batch biotransformation process of glycerol metabolism till today. These results indicated that our newly developed mutant can tolerate high concentration of glycerol, have a high glycerol utilization rate, and high product yield of 2,3-BD. It is demonstrated that the mutant strain $K$. pneumoniae SRM2 has an ability to produce fewer co-products at trace concentrations at higher glycerol concentrations, and could be a potential candidate for 2,3-DB production in an industrial bioconversion process.
\end{abstract}

Key words: Glycerol dehydrogenase, Crude glycerol, 2,3-Butanediol, Bioconversion, Klebsiella pneumoniae.

\section{Introduction}

Biodiesel has become one of the vibrant renewable fuels produced from animal fats and vegetable oils by reacting with a primary alcohol in the presence of an alkali or acid catalyst. During the last few years, biodiesel production has increased dramatically, and a significant amount $(10 \% \mathrm{v} / \mathrm{v})$ of crude glycerol is generating from a typical biodiesel production process. Crude glycerol produced from bio-refineries is a worldwide overflow problem due to a nonexistence of refining capacity. Thus, a high volume of crude glycerol is the key problem for growth of biodiesel industry. The economic feasibility of the biodiesel industry has been crucially affected due to a high volume (by worldwide surplus) of crude 
glycerol generated from biodiesel production process [1]. Therefore, with increasing biodiesel production plants, a large number of glycerol production plants will be shut down within few years due to price drop by oversupply of glycerol $[2,3]$ that require new commercial uses. Glycerol, a core by-product of biodiesel production has become an inexpensive and easily obtainable product for which new applications have to be discovered [1]. Several species of Enterobacteriaceae are capable for converting glycerol to produce value-added bio-products [5-7]. Until now, there is no effectual microorganism which can convert glycerol efficiently to produce industrially important high-priced products. Most of the studies have been carried out on bioconversion of glycerol using anaerobic fermentation process [1, 7]. Our primary focus is to enhance the production of 2,3-BD from glycerol by effective bacterial strain under completely aerobic process. However, for glycerol metabolism, the metabolic pathways of $K$. pneumoniae has been explored recently [8]. In K. pneumoniae, the metabolic process of glycerol bioconversion is accomplished by a complex two-branch (oxidative and reductive) pathways (Fig. 1), which results in the synthesis of major products including dihydroxyacetone (DHA), 2,3-BD, ethanol, acetoin, acetate and 1,3-propanedion (1,3-PDO). In the oxidative branch, an important cell-bounded (intracellular) and $\mathrm{NAD}^{+}$-dependent enzyme GDH converts glycerol to DHA, producing $\mathrm{NADH}$ as a reducing equivalent $[4,8]$. Subsequently, dihydroxyacetone phosphate (DHAP) is generated from DHA by ATP or phosphoenolpyruvatedepended DHA kinase, which is then further metabolized to various products through pyruvate [4, 8]. Meanwhile, NADH (reducing equivalent) produced after receiving electrons from oxidation of substrate organic compounds could stimulate 1,3-PDO production [8]. Moreover, glycerol is firstly converted to 3-hydroxypropionaldehyde (3-HPA) by the coenzyme $\mathrm{B}_{12}$-dependent glycerol dehydratase through the parallel reductive branch of glycerol metabolism, and it is then reduced to the major product 1,3-PDO by the NADH-linked 1,3-PDO dehydrogenase, thereby regenerating $\operatorname{NAD}^{+}[4,8]$.

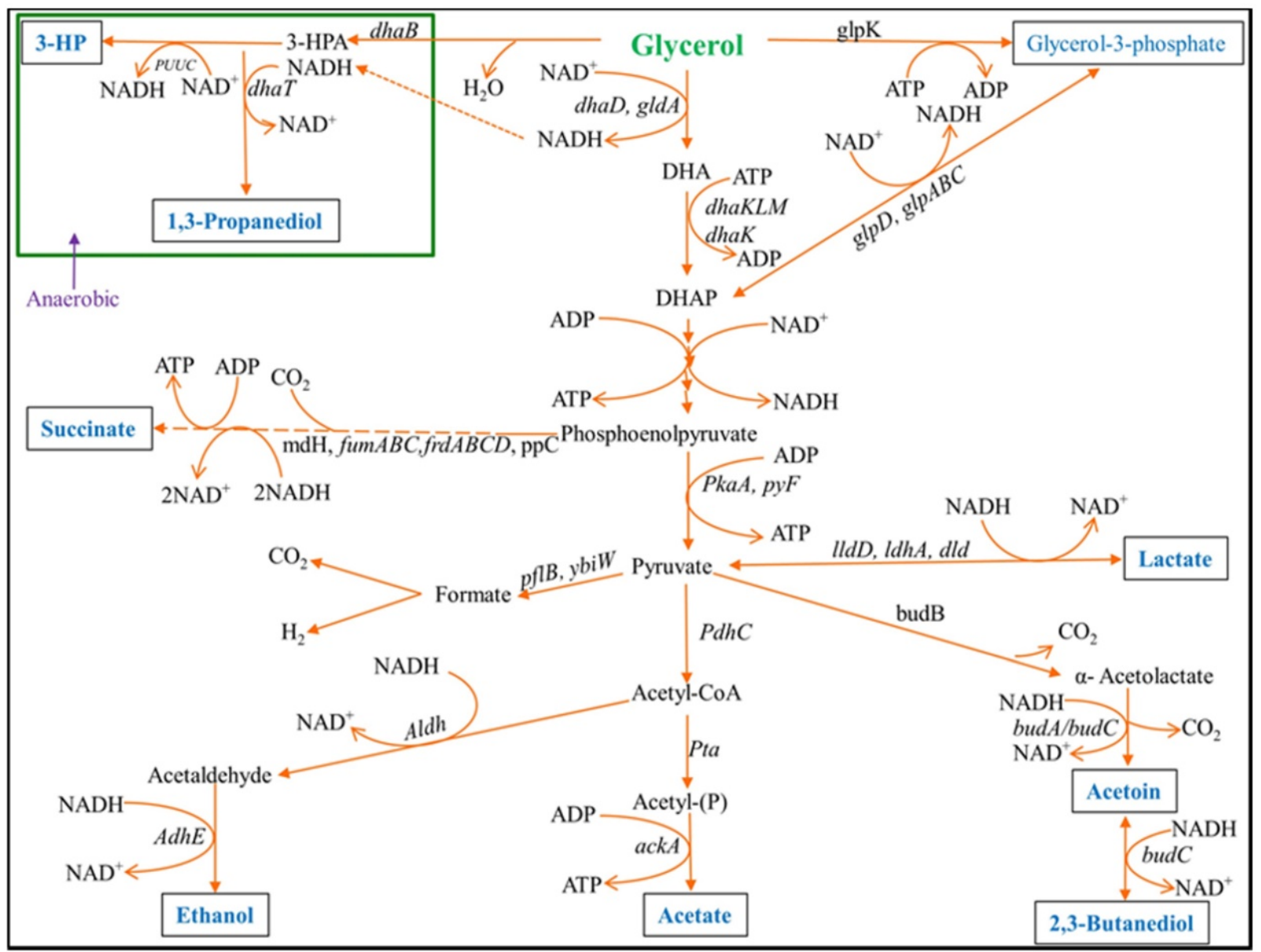

Figure 1. Initial steps of the glycerol dissimilation pathway together with 2,3-BD, 1,3-PDO, acetate and acetoin formation in Klebsiella. 3-HP: 3-Hydroxypropionic acid. 
The two important platform chemicals 2,3-BD and acetoin can be obtained from oxidative pathways of glycerol metabolisms of many bacteria [6, 9]. Acetoin, an important metabolic product of microorganisms is commonly used for the preparation of cosmetics, food, and many chemicals [10]. However, 2,3-BD is an expensive chemical which is used as a liquid fuel and fuel additive [11]. As an industrially important chemical, 2,3-BD is also extensively used for the preparation of pharmaceuticals and many synthetic materials [11, 12].

Recently, many species (Klebsiella planticola, K. oxytoca and K. pneumoniae) of the genus Klebsiella have been reported to produce 1,3-PDO as a principal product through bioconversion of glycerol, whereas 2,3-BD was the minor [9, 13-15]. In this study, metabolic products of batch and fed-batch fermentation of glycerol using a newly isolated strain K. pneumoniae SRP2 and its ethyl methane sulfonate (EMS) mutant was evaluated. Our goal was to optimize the culture conditions to gain expression of $\mathrm{GDH}$ as well as increase metabolic product yield of 2,3-BD to make a process relevant for industrial application. Here, we report a high product concentration of 2,3-BD from glycerol as a sole carbon source using our newly isolated strain K. pneumoniae SRP2 and its EMS mutant K. pneumoniae SRM2.

\section{Materials and Methods}

\section{Isolation of glycerol degrading bacterial strain}

K. pneumoniae SRP2 wild type and an EMS mutant SRM2 strains were used throughout this study. The strain K. pneumoniae SRP2 was isolated from paper mill waste of Resolute Forest Products, Canada. In order to isolate the glycerol degrading bacterial strain SRP2, the method described our earlier work [6] was followed. This isolated strain was further screened for their glycerol assimilation, GDH activity and 2,3-BD production. This strain was maintained at $4^{\circ} \mathrm{C}$ on Luria-Bertani (LB) agar slant and sub-cultured every two weeks.

\section{Identification of the bacterial strain}

The strain SRP2 was identified by $16 \mathrm{~S}$ rDNA sequencing, confirmed by its phenotypic and biochemical characteristics. The gene encoding 165 rRNA was amplified from the genomic DNA of SRP2 strain by PCR (polymerase chain reaction) using $16 \mathrm{~S}$ rDNA universal bacterial primer pairs, which were HDA-1 (5'-GACTCCTACGGGAGGCAGCAGT) and E1115R (5'-AGGGTTGCGCTCGTTGCGGG), and a $726 \mathrm{bp}$ fragment was obtained. The product obtained after PCR was purified using PCR purification Kit (Geneaid, Canada) following the manufacturer's protocol. The purified PCR sample was sent to Euroffins Genomics (USA) for sequencing. For identification of the strain SRP2, sequence analysis was performed using NCBI blast tool, compared with sequences of the Gene Bank database search (http://www.ncbi.nlm.nih.gov/genbank/). The phylogenetic relationship was analyzed using sequence alignment program ClustalX and TreeView software. The species identification was confirmed using phenotypic and biochemical features [16].

\section{Optimization of fermentation parameters}

Seed culture for batch and fed-batch processes was prepared from stock slant culture by inoculating into LB broth medium. The LB broth seed culture was incubated at $37^{\circ} \mathrm{C}$ and $180 \mathrm{rpm}$ for $20 \mathrm{~h}$. Following incubation, the seed culture was inoculated into appropriate medium for optimization of culture conditions such as incubation temperature and time, medium initial $\mathrm{pH}$, glycerol concentration, and nitrogen sources. All the growth parameters were performed in triplicates. For GDH enzyme and 2,3-BD assay, batch fermentations were maintained in $250 \mathrm{ml}$ $\mathrm{ml}$ Erlenmeyer flasks $(100 \mathrm{ml}$ medium and $100 \mu \mathrm{l}$ of 20 $\mathrm{h}$ culture as the inoculum) at different initial $\mathrm{pH}(4,5$, $6,7,8$ and 9$)$, temperatures $\left(25-40^{\circ} \mathrm{C}\right)$, and at different concentrations of glycerol $\left(25-65 \mathrm{~g} \mathrm{~L}^{-1}\right)$, yeast extract $\left(1.0-5.0 \mathrm{~g} \mathrm{~L}^{-1}\right)$ and peptone $\left(4.0-6.5 \mathrm{~g} \mathrm{~L}^{-1}\right)$. The minimal salt-1 (MS-1) medium $\left(\mathrm{KCl}, 0.1 \mathrm{~g} \mathrm{~L}^{-1}\right.$; $\mathrm{K}_{2} \mathrm{HPO}_{4}, 0.1 \mathrm{~g} \mathrm{~L}^{-1} ; \mathrm{MgSO}_{4} .7 \mathrm{H}_{2} \mathrm{O}, 0.05 \mathrm{~g} \mathrm{~L}^{-1}$ and $\mathrm{NaNO}_{3}, \quad 0.1 \mathrm{~g} \mathrm{~L}^{-1}$ ) supplemented with specified concentration of glycerol or crude glycerol and nitrogen sources was used throughout the experiments when indicated. Medium $\mathrm{pH}$ was adjusted using $\mathrm{HCl}(1 \mathrm{M}) / \mathrm{NaOH}(1 \mathrm{M})$. Biodiesel byproduct (crude glycerol) supplied by CARES (Centre for Agricultural Renewable Energy and sustainability) biodiesel plant (Guelph, Canada) was used as a feedstock (sole carbon source) for microbial growth throughout this study. This crude glycerol contains $50.0 \pm 4.6 \%$ glycerol.

\section{Batch and fed-batch fermentation under optimized conditions}

Batch and Fed-batch fermentations were carried out in $250 \mathrm{ml}$ Erlenmeyer flasks containing $100 \mathrm{ml}$ medium (initial $\mathrm{pH} 8.0$ ) with $100 \mu \mathrm{l}$ of $20 \mathrm{~h}$ culture as the inoculum, incubated at $37^{\circ} \mathrm{C}$ under aerobic condition at $180-200 \mathrm{rpm}$. The medium MS-2 used for batch and fed-batch cultures contained $\mathrm{KCl}\left(0.1 \mathrm{~g} \mathrm{~L}^{-1}\right)$, $\mathrm{K}_{2} \mathrm{HPO}_{4}\left(0.1 \mathrm{~g} \mathrm{~L}^{-1}\right), \mathrm{MgSO}_{4} .7 \mathrm{H}_{2} \mathrm{O}\left(0.05 \mathrm{~g} \mathrm{~L}^{-1}\right), \mathrm{NaNO}_{3}$ $\left(0.1 \mathrm{~g} \mathrm{~L}^{-1}\right)$, glycerol $\left(55.0 \mathrm{~g} \mathrm{~L}^{-1}\right)$ or crude glycerol (75.0 $\left.\mathrm{g} \mathrm{L}^{-1}\right)$, yeast extract $\left(2.5 \mathrm{~g} \mathrm{~L}^{-1}\right)$ and peptone $\left(4.5 \mathrm{~g} \mathrm{~L}^{-1}\right)$. In case of fed-batch culture, the glycerol concentrations were varied. In our fed-batch culture, 
an initial concentration of glycerol was $55 \mathrm{~g} \mathrm{~L}^{-1}$, and then a concentrated solution containing $800 \mathrm{~g} \mathrm{~L}^{-1}$ of pure glycerol or crude glycerol was fed into the culture as required.

\section{Enzyme Assay}

The enzyme assay of membrane-bounded GDH was carried out by measuring the initial reduction rate of NAD (from NAD to NADH) at $340 \mathrm{~nm}$ absorbance according to the established method [17] with minor modifications [6]. The reaction mixture used for GDH assay contained ammonium sulfate (30 $\mathrm{mM})$, glycerol $(0.2 \mathrm{M})$, potassium phosphate buffer (50 mM) and NAD (1.2 mM), which was prepared just before the enzyme assay. A 96 well microplate (flat bottom), each well with $1 \mathrm{~cm}$ light path length containing $250 \mu \mathrm{l}$ reaction mixture was used for GDH assay. The reaction was started by adding $50 \mu \mathrm{l}$ cell free extract of bacterial cells. One unit of GDH activity is defined as the amount of enzyme required to oxidize $1 \mu$ mole of substrate per minute. However, the specific activity of GDH is stated as pmoles of substrate reduced/minute/mg of cell protein. Protein was quantified using standard protocol [18] with bovine serum albumin as a standard protein.

\section{Strain development}

An adapted strain was developed from the wild type strain SRP2 using the method described in our previous study [6]. This evolutionary developed (adapted) strain was able to grow at a concentration of $220 \mathrm{~g} \mathrm{~L}^{-1}$ glycerol. The evolutionary adapted strain was mutagenized with UV coupled with EMS [19]. To get UV mutant, the inoculated culture plate was exposed to UV light at $280 \mathrm{~nm}$ wavelength for 3 minutes and $40 \mathrm{~cm}$ away from the light source. For EMS mutagenesis, the UV treated culture was used, and a standard method described by Jensen et al [20] was followed. Briefly, $0.1 \mathrm{ml}$ of $24 \mathrm{~h}$ LB broth culture was plated on MS-1 agar medium supplemented with $100 \mathrm{~g} \mathrm{~L}^{-1}$ glycerol. On the centre of the plate, a drop 6 $\mu \mathrm{l}$ EMS $(99 \%)$ was placed, incubated at $37^{\circ} \mathrm{C}$ for $72 \mathrm{~h}$. Following incubation, a bacterial colony grown at the edge and middle of EMS inhibition zone was taken, streaked on MS-1 agar medium containing $100 \mathrm{~g} \mathrm{~L}^{-1}$ glycerol, and tested its 2,3-BD product concentration.

\section{Toxicity test}

For toxicity test, the minimum inhibition concentration (MIC) and minimum bactericidal concentration (MBC) of glycerol were performed in batch culture. A series of culture medium (MS-1 supplemented with yeast extract $2.5 \mathrm{~g} \mathrm{~L}^{-1}$ ) tubes were prepared with different concentrations of glycerol ranging from 100 to $550 \mathrm{~g} \mathrm{~L}^{-1}$, inoculated with $100 \mu \mathrm{L}$ of a $20 \mathrm{~h}$ culture, and incubated at $37^{\circ} \mathrm{C}$ for $120 \mathrm{~h}$.
Following incubation, growth was evaluated spectrophotometrically based on the absorbance at $600 \mathrm{~nm}$ and the dry cell mass was measured by using a standard curve (a linear correlation between the dry cell mass and absorbance of cell suspension). For MBC, $100 \mu \mathrm{L}$ culture broth from each tube was plated on LB agar medium, and incubated at $37^{\circ} \mathrm{C}$ for $48 \mathrm{~h}$. After incubation, any growth was observed on the agar plate. All tests were conducted in at least triplicates.

\section{Assay of biomass and metabolic products}

Biomass was measured as absorbance at $600 \mathrm{~nm}$ using microplate spectrophotometer (EPOCH, BioTek) and converted to cell dry weight using a calibration equation $(\mathrm{y}=2.0978 \mathrm{x}-0.0346$, where $\mathrm{y}=$ OD600, $x=$ biomass $\mathrm{g} \mathrm{L}^{-1}$ ) obtained from standard curve of a linear correlation between the dry cell mass and absorbance of cell suspension (Figure S1). The identity of the end products was confirmed by GC-MS (Varian 1200 Quadrupole). Glycerol concentration (g $\mathrm{L}^{-1}$ ) and major metabolic products including 2,3-BD, acetoin, 1,3-PDO and acetic acid were determined by GC-FID (Shimatzu GC 14A) under the following conditions: sample volume $1 \mu \mathrm{l}$; column temperature range from $45^{\circ} \mathrm{C}(2 \mathrm{~min})$ to $240^{\circ} \mathrm{C}$ at the rate of $10^{\circ} \mathrm{C} / \mathrm{min}$; the injector and detector temperature $250^{\circ} \mathrm{C}$; carrier gas nitrogen; column DB-WAXetr. The injecting sample was purified by centrifugation and membrane filter $(0.22 \mu \mathrm{m}$ pores size).

\section{Results}

\section{Isolation and identification of bacterial strain}

The isolation procedure was primarily based on tolerance and ability to utilize glycerol $\left(100 \mathrm{~g} \mathrm{~L}^{-1}\right)$ as the sole carbon source to produce GDH enzyme under aerobic condition, and yielded a number of bacterial strains from soil and paper mill waste samples. Of these isolates, the strain SRP2 (K. pneumoniae) isolated from paper mill waste exhibited significant GDH activity. This highly active SRP2 strain was identified as genus Klebsiella (99\% similarity) using $16 \mathrm{~S}$ rRNA gene sequencing. By using phenotypic and biochemical characters shown in Table 1, the species $K$. pneumoniae (strain $K$. pneumoniae SRP2) was identified. On LB agar the strain SRP2 was found to grow as large mucoid and slimy (old culture) colonies. The morphological features observed by light microscopy are: rod-shaped and encapsulated cells, $0.4-0.8 \mu \mathrm{m}$ in diameter and 0.7-5.0 $\mu \mathrm{m}$ in length, arranged singly/ in pair/ in short chain.

The 16S rRNA sequences of the isolated strain SRP2 and its EMS mutant SRM2 have been submitted to the GenBank for accession numbers. The strains 
reported in this research article have been nominated as Klebsiella pneumoniae SRP2 (wild) and K. pneumoniae SRM2 (mutant), and their GenBank accession numbers are released as KR092086 and KX572902 respectively. However, for the phylogenetic relationship analysis, the $16 \mathrm{~S}$ rRNA gene sequences of SRP2 and its mutant SRM2 were aligned using ClustalX UPGMA algorithm and uploaded into TreeView (Fig. 2). The phylogenetic tree was built by the Neighbor-Joining method using 16S rRNA gene sequencing. The result of phylogenetic relationship confirmed that the strains belong to the genus Klebsiella or species K. pneumoniae. In phylogenetic tree the distance between the wild type (K. pneumoniae SRP2) and its mutant (K. pneumoniae SRM2) strains also confirmed mutagenesis.

Table 1. Morphological and physiological characters of strain $K$. pneumoniae SRP2

\begin{tabular}{ll}
\hline Characters & Results \\
\hline Gram staining (24h) & Gram - \\
Capsule & + \\
Indole production & - \\
$\mathrm{H}_{2}$ S production & - \\
Methyl red & + \\
Voges-Proskauer & + \\
Citrate & + \\
Urea hydrolysis & + \\
Gas/acid from Lactose $\left(44^{\circ} \mathrm{C}\right)$ & $+/+$ \\
Gas/acid from glucose & $+/+$ \\
Gelatin hydrolysis $\left(22^{\circ} \mathrm{C}\right)$ & - \\
KCN growth & + \\
Nitrate reduction & + \\
Lysine decarboxilate & + \\
Oxidase & - \\
Catalase & + \\
Acid from cellobiose, maltose, mannitol, arabinose, sucrose & + \\
and sorbitol. & \\
\hline +, positive; -, negative &
\end{tabular}

\section{Strain development}

The adapted strain obtained from $220 \mathrm{~g} \mathrm{~L}^{-1}$ glycerol was used to develop EMS mutant. Following incubation, a zone of inhibition was developed on the plates around the drop of EMS (Fig. 3). All the colonies obtained from the edge and middle of the inhibition zone were streaked on MS-1 agar plates with $100 \mathrm{~g} \mathrm{~L}^{-1}$ glycerol, and tested for their 2,3-BD production. The EMS mutagenesis revealed a high yielding 2,3-BD mutant marked as strain No. SRM2.

\section{Effect of growth factors on GDH activity and 2,3-BD production in batch culture}

In the oxidative pathway, GDH is a key enzyme for converting glycerol to biofuels and value-added metabolic products including DHA, 2,3-BD, acetoin and organic acids. To optimize glycerol concentration, incubation temperature and time, initial $\mathrm{pH}$ and nitrogen sources for maximum enzyme activity, experiments were carried out in batch fermentation (Fig 4-7). In this aerobic batch fermentation, glycerol was only the carbon source for microbial growth to produce GDH and 2,3-BD. The results revealed optimum initial concentrations $45 \mathrm{~g} \mathrm{~L}^{-1}$ and $55 \mathrm{~g} \mathrm{~L}^{-1}$ of glycerol for the strains SRP2 and SRM2 respectively, whereas the yeast extract concentration was $2.5 \mathrm{~g} \mathrm{~L}^{-1}$ at starting $\mathrm{pH} 7.0$ and incubation temperature $37^{\circ} \mathrm{C}$ (Fig 4). To optimize the incubation temperature for maximum GDH activity and 2,3-BD production of the both strains SRP2 and SRM2, experiments were performed in batch culture at starting $\mathrm{pH} 7.0$ under controlled temperatures ranging from 25 to $40^{\circ} \mathrm{C}$. The maximum enzyme activities 344.5 and 467.7 unit/mg protein were achieved at $37^{\circ} \mathrm{C}$ after $48 \mathrm{~h}$ incubation with the strains SRP2 and SRM2 respectively (Fig. 5). In case of 2,3-BD, the maximum concentrations $12.9 \mathrm{~g}$ $\mathrm{L}^{-1}$ and $15.0 \mathrm{~g} \mathrm{~L}^{-1}$ of $2,3-\mathrm{BD}$ were attained by the strains SRP2 and SRM2 respectively at the same temperature under the same conditions (Fig. 5). The mutant strain SRM2 exhibited 1.35 and 1.16-fold higher production of GDH and 2,3-BD respectively compared to that of its wild type SRP2 strain under same incubation conditions.

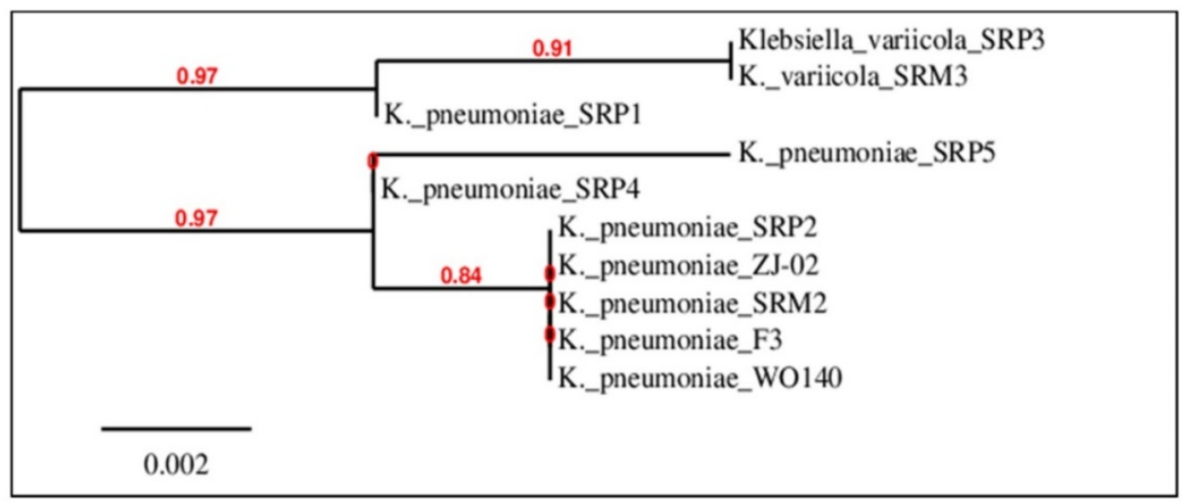

Figure 2. Phylogenetic tree drawn from ClustalX alignment, presented in TreeView. 

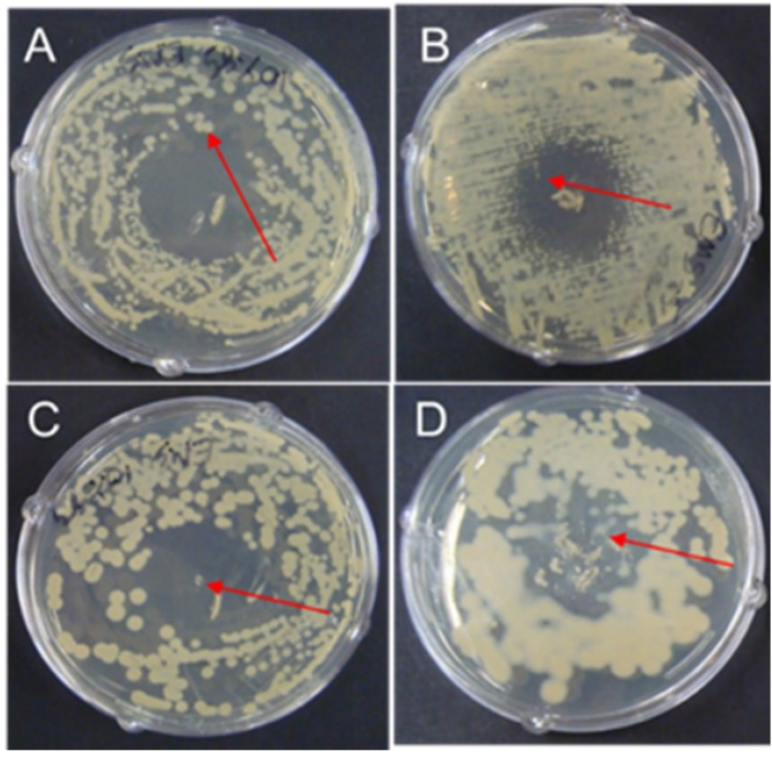

Figure 3. EMS treated culture plates $A, B, C$ and $D$ for possible mutant.

The initial $\mathrm{pH}$ of the medium played an important role for the production of GDH and 2,3-BD by SRP2 and SRM2 strains. Experiments without $\mathrm{pH}$ control showed that the higher was the starting $\mathrm{pH}$ values, the greater was the GDH activity and 2,3-BD concentration (Fig. 6a). Before autoclaving, the medium $\mathrm{pH}$ values (4-8) were adjusted using $\mathrm{HCl} / \mathrm{NaOH}$. A time course of $\mathrm{pH}$ and cell biomass changes with starting $\mathrm{pH} 8.0$ was performed over a period of $144 \mathrm{~h}$ (Fig. 6b). Fascinatingly, in the first 24 $\mathrm{h}$, the $\mathrm{pH}$ of the medium speedily dropped and reached values from 8.0 to 4.6. This first $24 \mathrm{~h}$ incubation period was the exponential growth phase of the batch culture and the $\mathrm{pH}$ was dropped due to the production of acetate and/ other organic acids in the culture medium. After $24 \mathrm{~h}$ incubation, the $\mathrm{pH}$ values were slightly rose and dropped during incubation and reached values between 4.6 and 5.5 due to production of 2,3-BD. Figure 6a shows that the maximum GDH activity (522.5 unit/mg protein) and 2,3-BD (17.5 $\left.\mathrm{g} \mathrm{L}^{-1}\right)$ production were attained at initial pH 8.0 by SRM2.

In addition to yeast extract $\left(2.5 \mathrm{~g} \mathrm{~L} \mathrm{~L}^{-1}\right)$, experiments were carried out on the effect of other nitrogen sources viz., malt, peptone, $\mathrm{NH}_{4} \mathrm{NO}_{3}$, $\left(\mathrm{NH}_{4}\right)_{2} \mathrm{SO}_{4}$ and $\mathrm{NH}_{4} \mathrm{Cl}$ for $\mathrm{GDH}$ and 2,3-BD production with the wild type strain SRP2 and its mutant SRM2.The peptone showed the highest GDH activity (616.7 unit/mg protein) and 2,3-BD product concentration (19.21 $\mathrm{g} \mathrm{L}^{-1}$ ) compared to that of other nitrogen sources with SRM2 strain (Fig 7a). The maximum GDH activity $638.6 \mathrm{unit} / \mathrm{mg}$ protein and $22.8 \mathrm{~g} \mathrm{~L}^{-1}$ were attained at a concentration of $4.5 \mathrm{~g} \mathrm{~L}^{-1}$ peptone after $48 \mathrm{~h}$ incubation by SRM2 (Fig. $7 \mathrm{~b}$ ).

\section{Toxicity test}

The mutated strain SRM2 was used for a toxicity test towards different concentrations of glycerol (Fig. 8). At an initial glycerol concentration of $300 \mathrm{~g} \mathrm{~L}^{-1}$, growth of SRM2 was detectable after $120 \mathrm{~h}$ incubation. However, at an initial glycerol concentration of $450 \mathrm{~g}$ $\mathrm{L}^{-1}$, viability of SRM2 strain was also detectable after cultured on LB agar. Based on these results strain SRM2 seemed most tolerant to glycerol. MIC and MBC of glycerol were determined as $350 \mathrm{~g} \mathrm{~L}^{-1}$ and 500 $\mathrm{g} \mathrm{L}^{-1}$ respectively (Fig. 8).

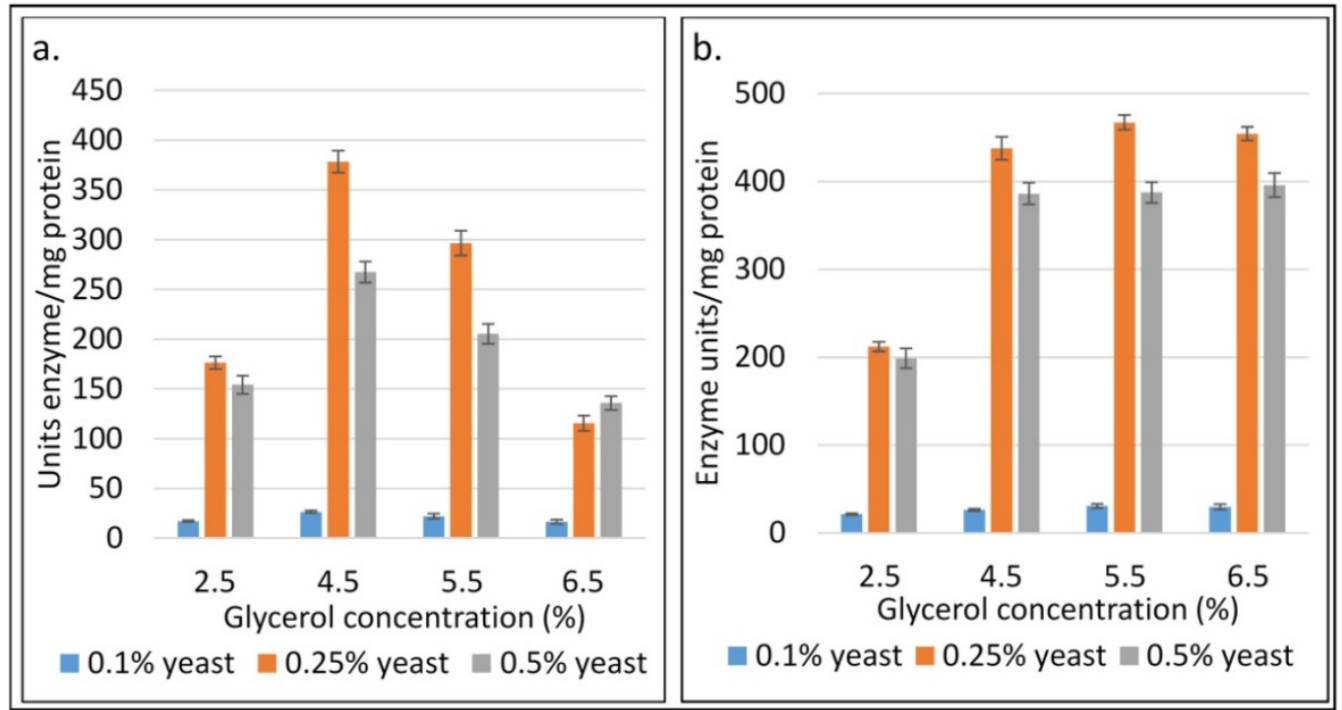

Figure 4. Influence of the concentrations of glycerol and yeast extract on GDH activity after $48 \mathrm{~h}$ at $37^{\circ} \mathrm{C}$ and initial $\mathrm{pH}$ 7.0. (a) Wild type $\mathrm{K}$. pneumoniae SRP2 (b) Mutant SRM2. 


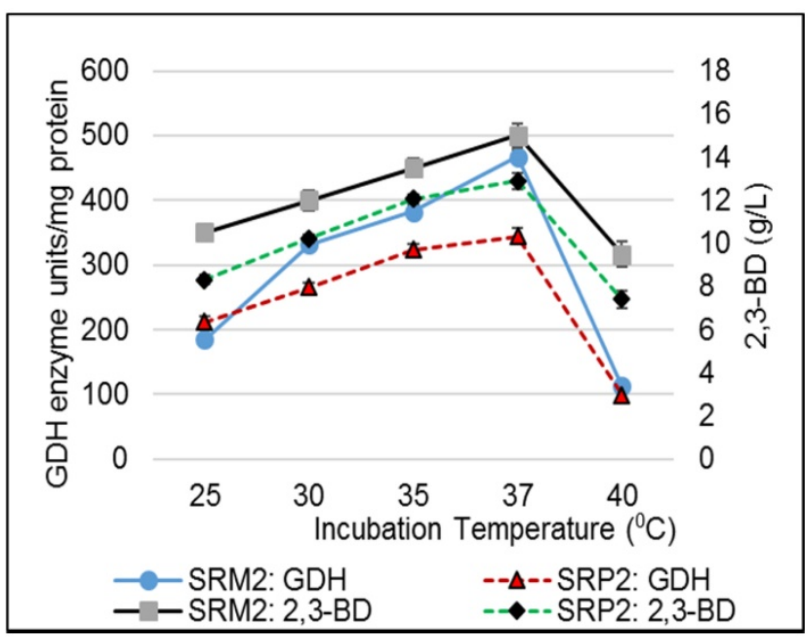

Figure 5. Influence of temperature on GDH activity and production of 2,3-BD of $K$. pneumoniae SRP2 and its mutant SRM2 after 48h at $370 \mathrm{C}$. MS-1 medium with glycerol $55.0 \mathrm{~g} \mathrm{~L}^{-1}$ and yeast extract $2.5 \mathrm{~g} \mathrm{~L}^{-1}$ was used. Medium initial $\mathrm{pH}$ was 7.0.

\section{Batch and fed-batch process under optimized conditions}

Batch and feed-batch cultivation processes were carried out under optimized conditions for maximizing 2,3-BD production. To investigate glycerol utilization and 2,3-BD production by $K$. pneumoniae SRP2 and its EMS mutant $K$. pneumoniae SRM2, batch cultures were performed with pure glycerol or crude glycerol as the sole carbon source at the initial concentration of $55.0 \mathrm{~g} \mathrm{~L}^{-1}$ and $75.0 \mathrm{~g} \mathrm{~L}^{-1}$ respectively. For quantification of bio-products, experiments were set at initial $\mathrm{pH} 8.0$ and temperature $37^{\circ} \mathrm{C}$. The medium used for both batch and fed batch cultures was MS-2. The above culture conditions revealed two major products $2,3-\mathrm{BD}$ and acetoin with other minor products including 1,3-PDO and acetate. In our batch process, a typical outline for aerobic bioconversion of pure glycerol by SRP2 and its mutant SRM2 at different incubation time, and production of end products are summarized in the Fig. 9. The K. pneumoniae SRP2 in this paper, utilized $100 \%$ of glycerol after $144 \mathrm{~h}$, generating $20.55 \pm 1.22 \mathrm{~g}$ $\mathrm{L}^{-1}$ 2,3-BD, $4.34 \pm 0.87 \mathrm{~g} \mathrm{~L}^{-1} 1,3-\mathrm{PDO}$ and $8.52 \pm 0.76 \mathrm{~g} \mathrm{~L}^{-1}$ acetoin in batch process. The maximum concentration and yield of 2,3-BD attained after $120 \mathrm{~h}$ incubation were $28.53 \pm 1.34 \mathrm{~g} \mathrm{~L} \mathrm{~L}^{-1}$ and $0.52 \mathrm{~g} / \mathrm{g}$ glycerol respectively (Fig. 9a). Nevertheless, a maximum $32.3 \mathrm{~g}$ $\mathrm{L}^{-1}$ of 2,3-BD was obtained from $55 \mathrm{~g} \mathrm{~L}^{-1}$ glycerol after $120 \mathrm{~h}$ incubation by SRM2, and the product yield was $0.59 \mathrm{~g} \mathrm{~g}^{-1}$ glycerol. The strain SRM2 utilized $100 \%$ of glycerol after $120 \mathrm{~h}$ incubation and the concentrations of major bio-products other than 2,3-BD determined in this batch culture after $120 \mathrm{~h}$ incubation were acetoin and 1,3-PDO, with concentrations, $6.7 \pm 0.64 \mathrm{~g}$ $\mathrm{L}^{-1}$ and $3.22 \pm 0.25 \mathrm{~g} \mathrm{~L}^{-1}$ respectively (Fig. 9b). SRM2 obtained from SRP2 by EMS mutagenesis was capable of grow in a high concentration $\left(220 \mathrm{~g} \mathrm{~L}^{-1}\right)$ of glycerol. Thus, the better adapted mutant strain SRM2 could efficiently convert glycerol to 2,3-BD and acetoin compared to that of its wild type strain SRP2. The maximum product concentrations and glycerol consumption were achieved from $96 \mathrm{~h}$ to $120 \mathrm{~h}$ incubation. In our batch culture, the highest concentrations of 1,3-PDO and acetoin obtained after $144 \mathrm{~h}$ were $3.56 \pm 0.73 \mathrm{~g} \mathrm{~L}^{-1}$ and $8.3 \pm 1.07 \mathrm{~g} \mathrm{~L}^{-1}$ respectively for SRM2, and $4.34 \pm 0.82 \mathrm{~g} \mathrm{~L}^{-1}$ and $8.52 \pm 1.14 \mathrm{~g} \mathrm{~L}^{-1}$ respectively for SRP2 (Fig. 9a and 9b). The major metabolic products obtained from this batch process of SRP2 and SRM2 were 2,3-BD, acetoin and 1,3-PDO, with a minor product acetic acid.

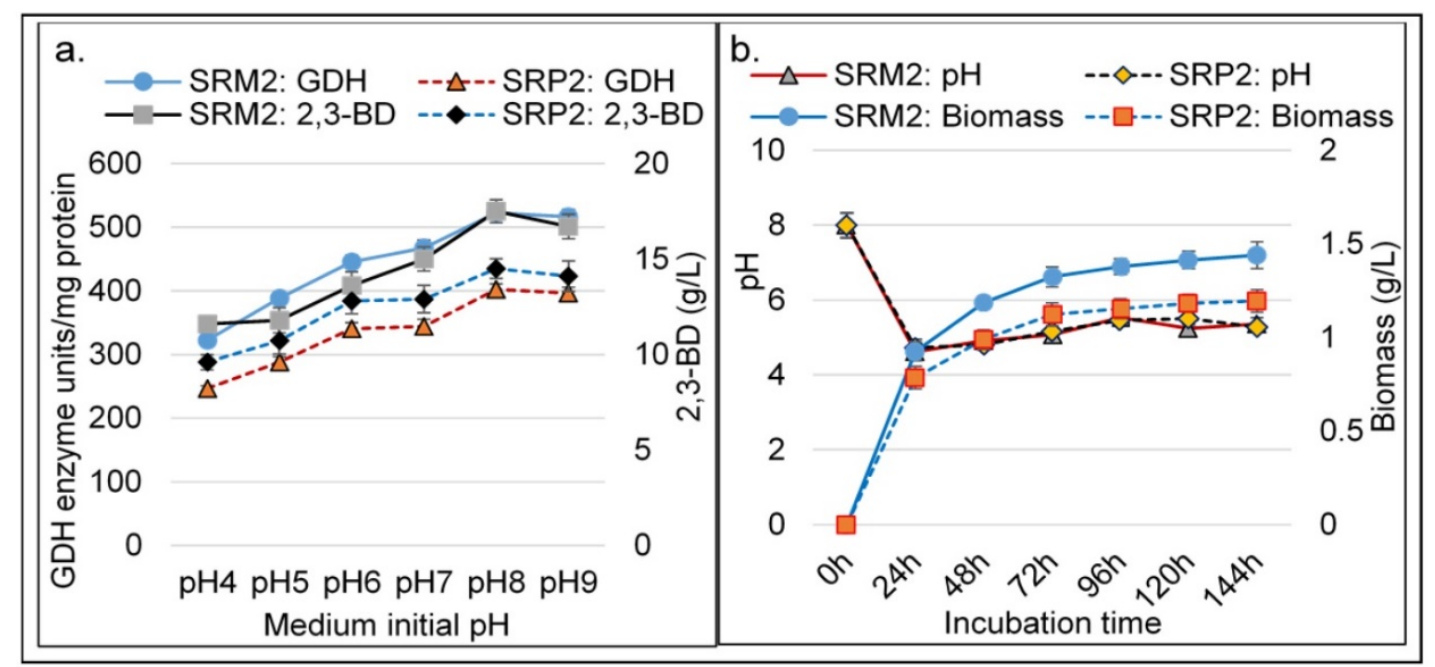

Figure 6. Effect of initial (starting) pH on $\mathrm{K}$. pneumoniae SRP2 and its mutant SRM2 at 370 C. (a) GDH and 2,3-BD production after 48h incubation. (b) Time profile of $\mathrm{pH}$ fluctuation and biomass production. MS-1 medium with glycerol $55.0 \mathrm{~g} \mathrm{~L}^{-1}$ and yeast extract $2.5 \mathrm{~g} \mathrm{~L}^{-1}$ was used. 


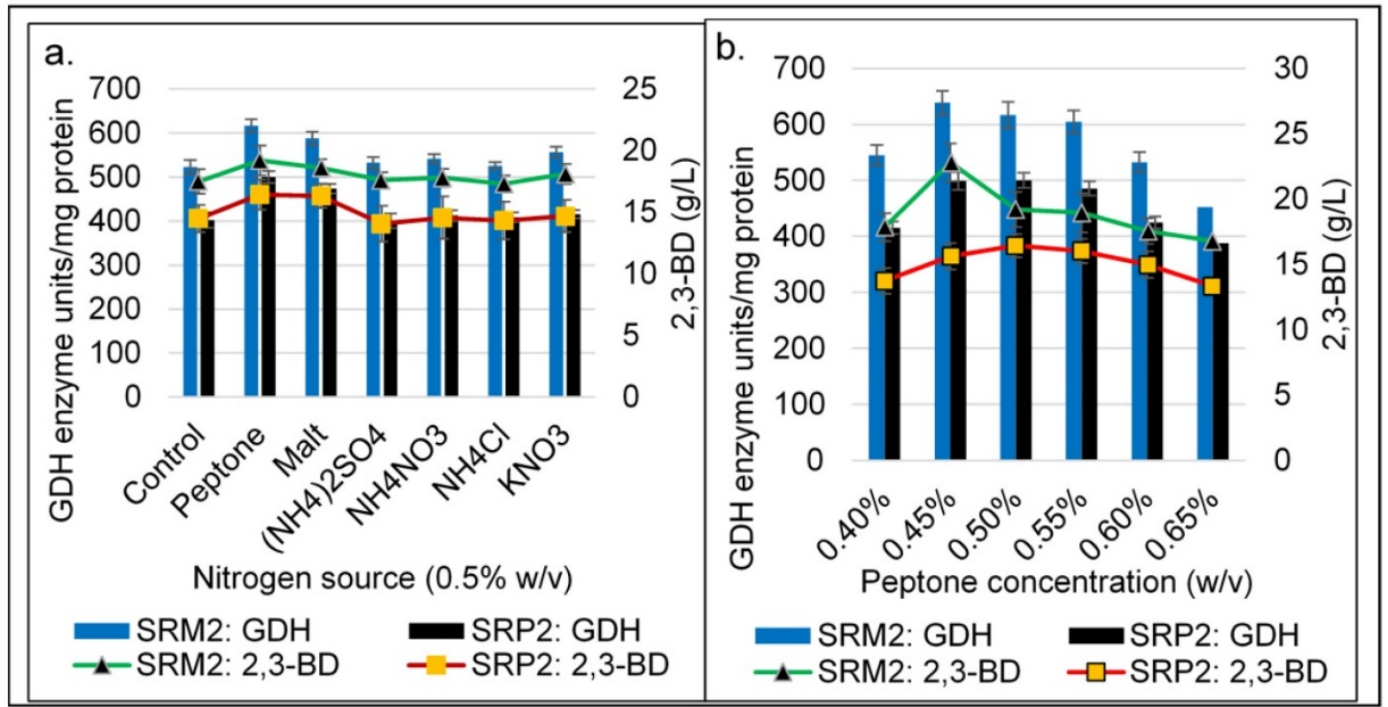

Figure 7. Influence of different nitrogen sources and peptone concentration on GDH and 2,3-BD production of $K$. pneumoniae SRP2 and its mutant SRM2 after $48 \mathrm{~h}$ at $37^{\circ} \mathrm{C}$. (a) Nitrogen sources. (b) Concentrations of peptone. MS-1 medium with glycerol $55.0 \mathrm{~g} \mathrm{L^{-1 }}$ and yeast extract $2.5 \mathrm{~g} \mathrm{~L}^{-1}$ was used. Medium initial $\mathrm{pH}$ was 8.0 .

To evaluate glycerol utilization and 2,3-BDO production from biodiesel derived crude glycerol (glycerol 50 $\pm 4.6 \%$, MONG 36.2 \pm 3.3 , ash $4.2 \pm 0.3 \%$ and water $6.7 \pm 1.05 \%$,) by strains SRP2 and SRM2, batch process was carried out at initial concentrations of $50.0-100.0 \mathrm{~g} \mathrm{~L}^{-1}$ of crude glycerol (Figure S2). The optimal concentration of this crude glycerol was attained as $75.0 \mathrm{~g} \mathrm{~L} \mathrm{~L}^{-1}$ for maximum product concentration of 2,3-BD. The effect of incubation time on SRP2 and SRM2 strains for accumulation of major products in a batch culture process of crude glycerol are presented in the Fig. 10. As shown in Figure 10, the performance of the 2,3-BD production by SRM2 was higher than compared to that of wild type strain SRP2. Overall, the mutated strain SRM2 could produce $27.7 \pm 0.83 \mathrm{~g} \mathrm{~L}^{-1} 2,3-\mathrm{BDO}$ as the principal product using $38.25 \mathrm{~g}$ glycerol after $120 \mathrm{~h}$ incubation

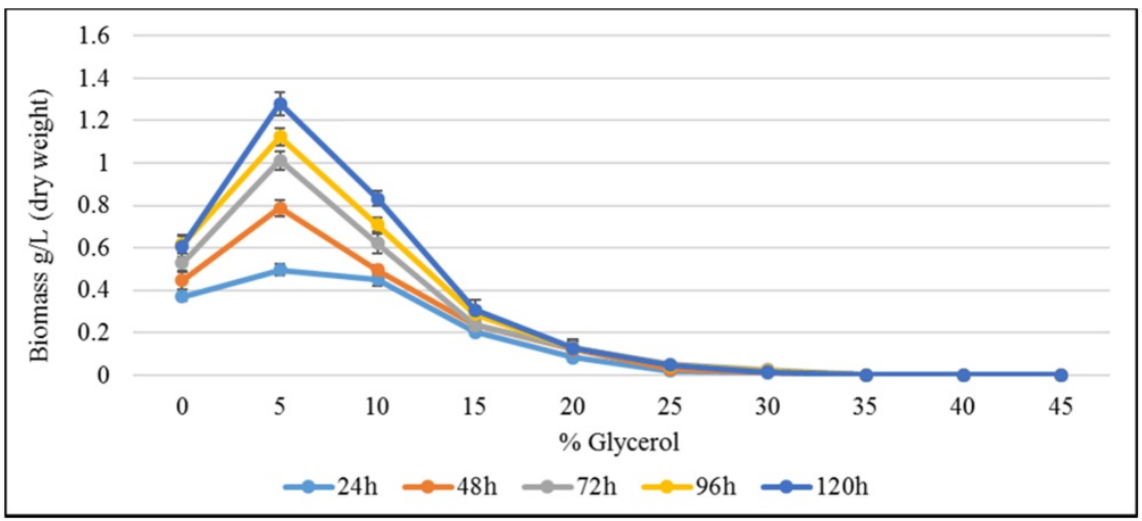

Figure 8. Toxicity [Minimum inhibitory concentration (MIC)] of glycerol against $K$. pneumoniae mutated strain SRM2 at initial pH 8.0. Incubation temperature was $370^{\circ} \mathrm{C}$. MS-1 medium with yeast extract $0.25 \%$ and peptone $0.45 \%$ was used.
(Fig. 10a). In this batch culture process, the highest concentrations of acetoin, 1,3-PDO and acetate obtained after $144 \mathrm{~h}$ were $5.78 \pm 0.21,2.79 \pm 0.2$ and $0.402 \pm 0.019 \mathrm{~g} \mathrm{~L}^{-1}$ respectively with the strain SRM2 (Fig. 10b). However, the strain SRP2 exhibited the highest 2,3-BD production $\left(25.73 \pm 1.04 \mathrm{~g} \mathrm{~L}^{-1}\right)$ after 120h incubation using $35.4 \mathrm{~g}$ glycerol (Fig. 10a).

In fed-batch process without $\mathrm{pH}$ control, the bioconversion kinetics showed that SRM2 produced high concentration of the principal product 2,3-BD in aerobic condition. Comparison between the final values of glycerol or biodiesel derived crude glycerol consumed, the biomass and major end products obtained by wild type strain SRP2 and EMS mutant SRM2 in fed-batch process are presented in Table 2. Table 2 shows that $51.1 \pm 1.7 \mathrm{~g} \mathrm{~L}^{-1}$, a high production of 2,3- BD was obtained after $240 \mathrm{~h}$ incubation, consumed $77.4 \mathrm{~g}$ glycerol from $148.8 \mathrm{~g} \mathrm{~L} \mathrm{~L}^{-1}$ biodiesel derived crude glycerol by SRM2. In case of pure glycerol, the highest concentration of 2,3-BD $\left(77.51 \pm 2.03 \mathrm{~g} \mathrm{~L}^{-1}\right)$ obtained after $240 \mathrm{~h}$ incubation by consumed $132.0 \mathrm{~g}$ glycerol. However, the wild type strain SRP2 exhibited $54.3 \pm 1.1 \quad \mathrm{~g} / \mathrm{L} \quad 2,3-\mathrm{BD}$ by consumed $91.1 \mathrm{~g}$ glycerol after 192h incubation. 


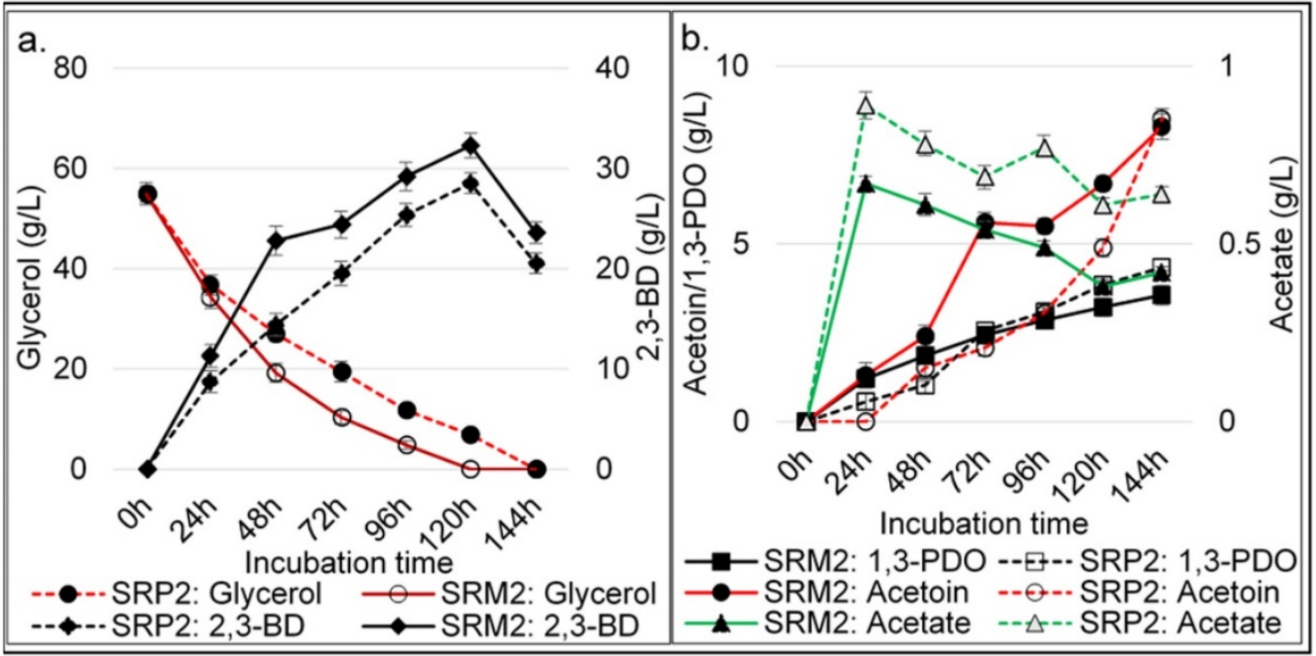

Figure 9. Time course data and metabolic products of batch cultivation at $37^{\circ} \mathrm{C}$ by wild type strain SRP2 and its mutant SRM2 of $K$. pneumoniae. (a) Glycerol and 2,3-BD concentrations. (b) Acetoin, 1,3-PDO and acetate concentrations. MS-2 medium with pure glycerol 55.0 $\mathrm{g} \mathrm{L}^{-1}$ was used. Medium initial pH was 8.0.

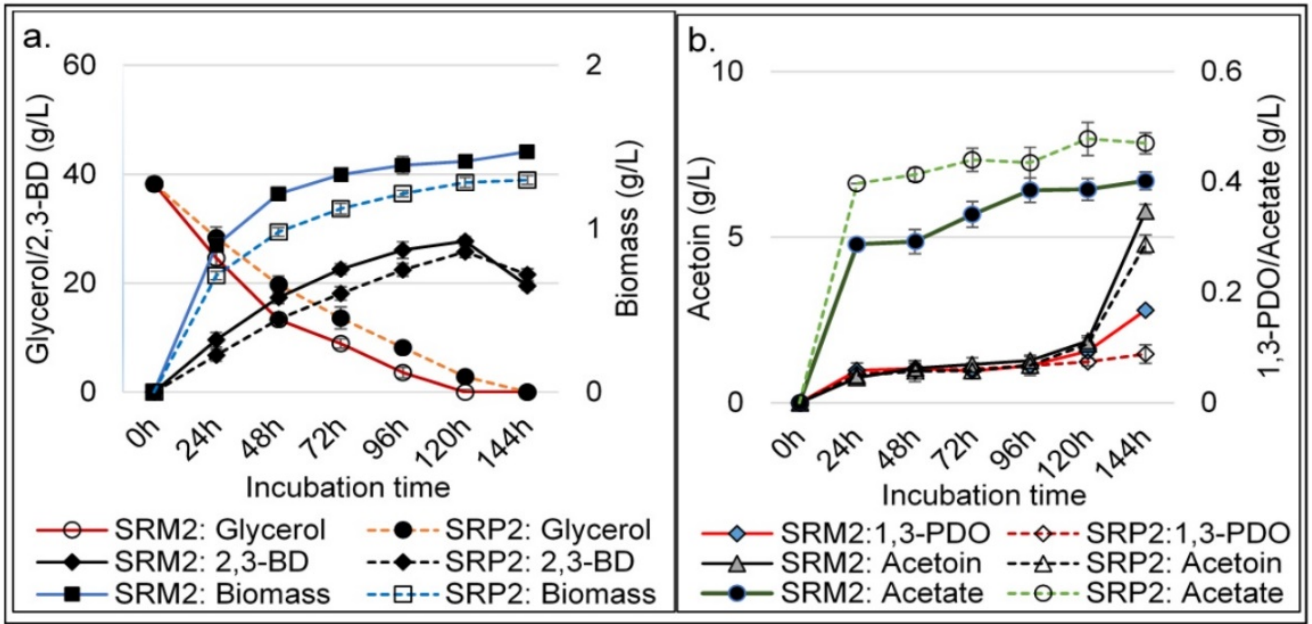

Figure 10. Time course data and metabolic products of batch cultivation at $370^{\circ} \mathrm{C}$ by wild type strain SRP2 and its mutant SRM2 of $K$. pneumoniae. (a) Glycerol and 2,3-BD concentrations. (b) Acetoin, 1,3-PDO and acetate concentrations. MS-2 medium with biodiesel derived crude glycerol 75.0 g $\mathrm{L}^{-1}$ was used. Medium initial $\mathrm{pH}$ was 8.0 .

Table 2. Comparison the final values of major products obtained from metabolized of glycerol by K. pneumoniae SRP2 and SRM2 strains in feed-batch process at initial $\mathrm{pH} 8$.

\begin{tabular}{|c|c|c|c|c|c|c|c|c|c|c|}
\hline \multirow[t]{2}{*}{ Strain } & \multirow{2}{*}{$\begin{array}{l}\text { Duration } \\
\text { (Hour) }\end{array}$} & \multirow{2}{*}{$\begin{array}{l}\text { Final } \\
\mathrm{pH}\end{array}$} & \multirow{2}{*}{$\begin{array}{l}\text { Biom. } \\
\text { (g/L) }\end{array}$} & \multirow{2}{*}{$\begin{array}{l}\text { Glycerol } \\
\text { utilized (g/L) }\end{array}$} & \multicolumn{2}{|c|}{ 2,3-BD } & \multicolumn{2}{|c|}{ Acetoin } & \multicolumn{2}{|c|}{ 1,3-PDO } \\
\hline & & & & & $(\mathrm{g} / \mathrm{L})$ & $\begin{array}{l}\text { Yield } \\
\text { (g/g) }\end{array}$ & $(\mathrm{g} / \mathrm{L})$ & $\begin{array}{l}\text { Yield } \\
\text { (g/g) }\end{array}$ & $(\mathrm{g} / \mathrm{L})$ & $\begin{array}{c}\text { Yield } \\
(\mathrm{g} / \mathrm{g})\end{array}$ \\
\hline SRP2 & 192 & 5.46 & 1.49 & 91.1 & $54.3 \pm 1.1$ & 0.60 & $6.1 \pm 0.6$ & 0.07 & $2.22 \pm 0.06$ & 0.02 \\
\hline SRM2 & 240 & 5.74 & 1.68 & 132.0 & $77.5 \pm 2.0$ & 0.59 & $7.8 \pm 0.5$ & 0.06 & $1.76 \pm 0.05$ & 0.01 \\
\hline CSRP2 & 192 & 6.52 & 1.63 & 68.82 & $40.2 \pm 1.7$ & 0.58 & $4.4 \pm 0.2$ & 0.06 & $1.23 \pm 0.04$ & 0.02 \\
\hline CSRM2 & 240 & 6.12 & 2.17 & 77.4 & $51.1 \pm 1.7$ & 0.66 & $5.5 \pm 0.4$ & 0.07 & $1.85 \pm 0.12$ & 0.02 \\
\hline
\end{tabular}

All experimental values presented are mean values from triplicate experiments;

Biom.: Dry weight of biomass;

cCrude glycerol was used as carbon source for this strain

\section{Discussion}

With the thriving of biodiesel industry, global surplus of glycerol is increasing [1,21]. Due to oversupply of crude glycerol from biodiesel refinery the glycerol price would be significantly affected, and several glycerol production plants will be shutdown [22]. Therefore, bioconversion of glycerol to value-added bio-products would lead to both environmental and economic dividends of biodiesel plant. Microbial conversion of glycerol to valuable chemicals is a subject of interest in the last few years 
$[23,24]$. Considering the glycerol bioconversion into biofuels and value-added bio-products, most of the recent studies focused on anaerobic fermentation process, and many microorganisms are able to utilize glycerol as a sole carbon source anaerobically $[20,24]$. Recently, several attempts have been made to produce value-added metabolic products including ethanol, 1,3-PDO and $\mathrm{H}_{2}$ from glycerol under anaerobic fermentation process $[23,25]$, but very limited studies have been done for aerobic processes. There is no any external electron acceptor in anaerobic fermentation, and the microbial growth is hampered. To overcome this problem in an anaerobic process, this study may be a viewpoint for high production of 2,3-BD as a major product of glycerol conversion in an aerobic process, and turning 1,3-PDO into a minor by-product. Considering economic utilize of glycerol, a goal was achieved to isolate an effectual bacterial strain, and develop the strain for high yield of 2,3-BD from crude and pure glycerol conversion.

K. pneumoniae, an enteric bacterium has long been considered to produce 1,3-PDO from glycerol as a feedstock in an anaerobic process $[7,15]$. Recently, a few works have been done on 2,3-BD production in an aerobic process $[12,26]$. We have demonstrated, however, that our newly isolated strain K. pneumoniae SRP2, and its mutants SRM2 could aerobically metabolize glycerol in a GDH-dependent oxidative pathway, and produce significant amount of industrially important product 2,3-BD together with other minor co-products. Furthermore, keeping the conditions defined in this study, the high production $32.3 \mathrm{gL}^{-1}$ and $77.51 \mathrm{gL}^{-1}$ of 2,3-BD was achieved from batch and fed-batch processes respectively by the mutant SRM2, as these amounts were the highest obtained from glycerol conversion reported. Therefore, in this study, the batch process with $55.0 \mathrm{~g}$ $\mathrm{L}^{-1}$ of initial glycerol was the optimal concentration for maximum GDH activity and 2,3-BD production, which is the highest glycerol concentration in batch culture (Fig. 5). Recently, Petrov and Petrova [26] studied on glycerol bioconversion by K. pneumoniae in fed-batch process, and showed the highest concentration $70.0 \mathrm{gL}^{-1}$ of 2,3-BD as well as $0.53 \mathrm{~g} / \mathrm{g}$ product yield. Interestingly, the mutant strain grew on and tolerated a high glycerol concentration up until $220.0 \mathrm{gL}^{-1}$. Moreover, the glycerol, a feed stock for 2,3-BD production is less toxic to the mutant due to its high MIC and MBC values. This research confirmed that a high glycerol concentration, up until $55 \mathrm{~g} / \mathrm{L}$ of feedstock concentration displayed maximum production yield of the metabolic product 2,3-BD, which could be the new prospect of glycerol bioconversion field.

Chemical mutagenesis, is a well-known and extensively used method for increasing tolerance towards an inhibitor of a microbial strain. Therefore, this increased tolerance may lead down-regulation of gene(s) accountable for the expected product [27]. EMS, a widely used chemical mutagen induces base replacements or deletions of DNA in a bacterium [28, 29] that may then gain an ability of higher productivity of a targeted product [23, 31]. Our achievement with increased tolerance towards glycerol and increased 2,3-BD production by EMS mutagenesis confirmed the competence of EMS for development of K. pneumoniae SRM2 mutant.

In our batch process of K. pneumoniae SRM2, maintained at different initial $\mathrm{pH}$ levels $(\mathrm{pH} 4-9)$, discovered that slightly alkaline $\mathrm{pH} 8$ was more favorable for the synthesis of 2,3-BD. This aerobic bioconversion of glycerol evidenced that the amount of the produced 2,3-BD from glycerol depends on the initial $\mathrm{pH}$ as well as other factors like temperature, initial concentration of glycerol and nitrogen sources.

We have demonstrated, however, that $K$. pneumoniae can utilize glycerol to produce 2,3-BD through oxidative pathway in a GDH-dependent manner. Clearly, the GDH enzyme plays a key role in oxidative pathway of glycerol metabolism and 2,3-BD formation. The establishment of optimal conditions including $\mathrm{pH}$, incubation temperature and nitrogen sources for 2,3-BD synthesis must comprise enhancement of GDH in oxidative pathway of the bioconversion process of glycerol.

\section{Conclusion}

Under aerobic conditions, 2,3-BD production from glycerol by K. pneumoniae mutant resulted in increased product yield and concentration in culture medium. The mutant strain K. pneumoniae SRM2 can tolerate high concentration of glycerol, have a high glycerol utilization rate, and high product yield of 2,3-BD. It is demonstrated that K. pneumoniae SRM2 has an ability to produce fewer co-products at trace concentrations at higher glycerol concentrations. Thus, the mutated strain SRM2 is a better organism for the aerobic conversion of glycerol to 2,3-BD. Therefore, we can conclude that it can metabolize high concentrations of glycerol and effectively convert the same to 2,3-BD and acetoin.

\section{Supplementary Material}

Supplementary figures and tables.

http://www.ijbs.com/v13p0308s1.pdf

\section{Acknowledgement}

We acknowledge the financial support of the BioFuelNet Canada (Project No. 67) and Lakehead University, Canada. 


\section{Competing Interests}

The authors have declared that no competing interest exists.

\section{References}

1. Yang F, Hanna MA, Sun R. Value-added uses for crude glycerol, a byproduct of biodiesel production. Biotechnol Biofuels. 2012; 5:13-22.

2. McCoy M. Glycerol surplus: Plants are closing and new uses for the chemical are being found. Chem Eng News. 2006; 84: 87-97.

3. Nanda MR, Yuan Z, Qin W, Ghaziaskar HS, Poirier M, Xu C. Thermodynamic and kinetic studies of a catalytic process to convert glycerol into solketal as an oxygenated fuel additive. Fuel. 2014; 117: 470-7.

4. Wang W, Sun J, Hartlep M, Deckwer WD, Zeng AP. Combined use of proteomic analysis and enzyme activity assays for metabolic pathway analysis of glycerol fermentation by Klebsiella pneumoniae. Biotechnol Bioeng. 2003; 83: $525-36$.

5. Dharmadi Y, Murarka A, Gonzalez R. Anaerobic fermentation of glycerol by Escherichia coli: a new platform for metabolic engineering. Biotechnol Bioeng. 2006; 94:821-9.

6. Rahman MS, Yuan Z, Ma K, Xu CC, Qin W. Aerobic Conversion of Glycerol to 2,3-Butanediol by a Novel Klebsiella variicola SRP3 Strain. J Microb Biochem Technol. 2015; 7:299-304.

7. Mu Y, Teng H, Zhang DJ, Wang W, Xiu ZL. Microbial production of 1,3-propanediol by Klebsiella pneumonia using crude glycerol from biodiesel preparations. Biotechnol Lett. 2006; 28: 1755-9.

8. Ashok S, Mohan RS, Ko Y, Sankaranarayanan M, Zhou S, Kumar V, Park S. Effect of puuC overexpression and nitrate addition on glycerol metabolism and anaerobic 3-hydroxypropionic acid production in recombinant Klebsiella pneumoniae $\Delta$ glpK $\Delta$ dhaT. Metab Eng. 2013; 15: 10-24.

9. Biebl H, Zeng AP, Menzel K, Deckwer WD. Fermentation of glycerol to 1,3-propanediol and 2,3-butanediol by Klebsiella pneumoniae. Appl Microbiol Biotechnol. 1998; 50:24-29.

10. Xiao Z, Ma C, Xu P, Lu JR. Acetoin Catabolism and Acetyl butanediol Formation by Bacillus pumilus in a Chemically Defined Medium. PLoS ONE. 2009; 4: e5627.

11. Li L, Zhang L, Li K, Wang Y, Gao C, Han B, et al. A newly isolated Bacillus licheniformis strain thermophilically produces 2,3-butanediol, a platform and fuel bio-chemical. Biotechnol Biofuels. 2013; 6:123-35.

12. Ma C, Wang A, Qin J, Li L, Ai X, Jiang T, Tang H, Xu P: Enhanced 2,3-butanediol production by Klebsiella pneumoniae SDM. Appl Microbiol Biotechnol. 2009, 82:49-57.

13. Jarvis GN, Moore ERB, Thiele JH. Formate and ethanol are the major products of glycerol fermentation produced by a Klebsiella planticola strain isolated from red deer. J Appl Microbiol. 1997; 83:166-74.

14. Yang G, Tian J, Li J. Fermentation of 1, 3-propanediol by a lactate deficient mutant of Klebsiella oxytoca under microaerobic conditions. App Microbiol Biotechnol. 2007; 73:1017-24.

15. Liu HJ, Zhang DJ, Xu YH, Mu Y, Sun YQ, Xiu ZL. Microbial production of 1, 3-propanediol from glycerol by Klebsiella pneumoniae under micro-aerobic conditions up to a pilot scale. Biotechnol let. 2007; 29:1281-5.

16. Holt JG, Krieg NR, Sneath PHA, Staley JT, Williams ST. Bergey's manual of determinative bacteriology, $9^{\text {th }}$ Ed. Baltimore, Maryland 1994

17. Ahrens K, Menzel K, Zeng A, Deckwer W. Kinetic, dynamic, and pathway studies of glycerol metabolism by Klebsiella pneumoniae in anaerobic continuous culture: III. Enzymes and fluxes of glycerol dissimilation and 1,3-propanediol formation. Biotechnol Bioeng. 1998; 59:544-52.

18. Bradford MM. A rapid and sensitive method for the quantitation of microgram quantities of protein utilizing the principle of protein-dye binding. Analytical biochem. 1976; 72: 248-54.

19. Miller JH. A short course in bacterial genetics: a laboratory manual and handbook for Escherichia coli and related bacteria. Cold Spring Harbor Press, NewYork. 1992

20. Jensen TØ, Kvist T, Mikkelsen MJ, Westermann P. Production of 1,3-PDO and butanol by a mutant strain of Clostridium pasteurianum with increased tolerance towards crude glycerol. AMB Express. 2012; 2:44- 9 .

21. Maksimov AL, Nekhaev AI, Ramazanov DN, Arinicheva YA, Dzyubenko AA, Khadzhiev S.N. Preparation of high-octane oxygenate fuel components from plant derived polyols. Pet Chem. 2011; 51: 61-9.

22. Delfort B, Duran I, Jaecker A, Lacome T, Montagne X, Paille F. Diesel fuel compound containing glycerol acetal. US Patent $6,890,364 ; 2005$.

23. Murarka A, Dharmadi Y, Yazdani SS, Gonzalez R. Fermentative utilization of glycerol in Escherichia coli and its implications for the production of fuels and chemicals. App Environ Microbiol. 2008; 74:1124-35.

24. Silva GP, Mack M, Centiero J. Glycerol: A promosing and abundant carbon source for industrial icrobiology. Biotech Adv. 2009; 27: 30-9.

25. Solomon BO, Zeng AP, Biebl H, Ejiofor A, Posten C, Deckwer WD. Effects of substrate limitation on product distribution and $\mathrm{H}_{2} / \mathrm{CO}_{2}$ ratio in Klebsiella pneumoniae during anaerobic fermentation of glycerol. Appl Microbiol Biotechnol. 1994; 42:222-6.

26. Petrov K, Petrova P. Enhanced production of 2, 3-butanediol from glycerol by forced $\mathrm{pH}$ fluctuations. Appl microbiol biotechnol. 2010; 87:943-9.
27. Borden JR, Papoutsakis ET. Dynamics of genomic-library enrichment and identification of solvent tolerance genes for Clostridium acetobutylicum. Appl Environ Microbiol. 2007; 73:3061-8.

28. Annous BA, Blaschek HP. Isolation and characterization of Clostridium acetobutylicum with enhanced amylolytic activity. Appl Environ Microbiol. 1991; 57:2544-8.

29. Elkanouni A, Junelles AM, Janatiidrissi R, Petitdemange H, Gay R. Clostridium acetobutylicum mutants isolated for resistance to the pyruvate halogen analogs. Curr Microbiol. 1989; 18:139-44.

30. Lemmel SA. Mutagenesis in Clostridium acetobutylicum. Biotechnol Lett. 1985; 7(10):711-6.

31. Syed QUA, Nadeem M, Nelofer R. Enhanced butanol production by mutant strains of Clostridium acetobutylicum in molasses medium. Turk J Biochem. 2008; 33:25-30. 